\title{
A method for the selection of Lactococcus lactis mutants producing excess
}

\author{
carbon dioxide
}

\author{
AISHA EL ATTAR, CHRISTOPHE MONNET, FRÉDÉRIC AYMES*
}

AND GEORGES CORRIEU

\begin{abstract}
Laboratoire de Génie et Microbiologie des Procédés Alimentaires, Institut National de la Recherche Agronomique, 78850 Thiverval-Grignon, France

Shortened title: Carbon dioxide-producing mutants

\section{Corresponding author:}

Christophe MONNET

INRA, Laboratoire de Génie et Microbiologie des Procédés Alimentaires,

78850 Thiverval-Grignon, France

TEL: ++ 33 (0) 130815491

20

FAX: ++ $33(0) 130815597$

E-mail: monnet@platon.grignon.inra.fr 
One of the characteristics of Roquefort cheese is the presence of irregularly shaped openings. Although many factors affect the development of opening in blue-veined cheeses (Martley \& Crow, 1996), the limiting step in the case of Roquefort cheese is the production of carbon dioxide by lactic acid bacteria (J.-P. Reverbel, personal communication). Most of the opening occurs after moulding, the process is difficult to control and many manufacturing runs result in cheeses with an insufficient opening. Concentrated suspensions of Leuconostoc strains are used to increase the production of carbon dioxide (Devoyod \& Muller, 1969), but it would clearly be of use to have microorganisms that produce larger quantities of the gas. McKay \& Baldwin (1973) isolated a spontaneous mutant of Lactococcus lactis that produced more acetoin and carbon dioxide than the parental strain. This mutant was lactate dehydrogenase (LDH) deficient, that favoured the conversion of pyruvate into end products other than lactate. Following nitrosoguanidine mutagenesis, we isolated three Lc. lactis mutants whose LDH activities were reduced to varying extents and which led to variable production of carbon dioxide (Boumerdassi et al. 1997). Subsequent work showed that these mutants were unstable on successive subcultures in milk or synthetic broth (unpublished results).

The aim of this work was to select a large number of Lc. lactis mutants producing excess carbon dioxide. This would increase the probability of selecting stable mutants and also provide a collection of strains with differing gas production activities. Currently available screening methods, however, are inconsistent with processing large numbers of mutants. This is why we developed an improved screening method. 


\section{MATERIALS AND METHODS}

\section{Strains used}

Lactococcus lactis subsp. lactis biovar. diacetylactis RD311 was obtained from Texel (F-86220 Dangé-Saint-Romain, France) and CNRZ 483 from the lactic acid bacteria collection of the Institut National de la Recherche Agronomique of Jouy-en-Josas (F-78352 Jouy-en-Josas, France). Strains 483L1 and 483L2 are mutants with attenuated LDH activity isolated by Boumerdassi et al. (1997) from strain CNRZ 483.

\section{Mutagen treatments}

Strain RD311 was grown at $30^{\circ} \mathrm{C}$ in $10 \mathrm{ml}$ of M17 broth (Terzaghi \& Sandine, 1975). Cells were harvested at the end of the exponential phase of growth by centrifugation, washed with $10 \mathrm{ml}$ of $0.1 \mathrm{M} \mathrm{Na}$ phosphate buffer, $\mathrm{pH} 7$ and resuspended in $1 \mathrm{ml}$ of buffer. Treatments with $N$-methyl- $N$ '-nitro- $N$-nitrosoguanidine (NTG) were carried out by mixing the cell suspension with $1 \mathrm{ml}$ of solutions of varying NTG concentrations, and incubating for $1 \mathrm{~h}$ at $30^{\circ} \mathrm{C}$. The cells were recovered by centrifugation, washed with $10 \mathrm{ml}$ of $\mathrm{Na}$ phosphate buffer and resuspended in $10 \mathrm{ml}$ of M17 broth. After incubating for $1 \mathrm{~h}$ at $30^{\circ} \mathrm{C}$, the culture was diluted 100 times in the buffer and dispersed with a mechanical blender (Ultra-Turrax ${ }^{\circledR}$ model T25; Ika Labortechnik, D-79217 Staufen, Germany) for 1 min. The cells were then inoculated in screening medium to obtain about 1000 colonies per Petri dish. When spontaneous mutants were sought, the same protocol was used, replacing the NTG solution with the buffer. When mutagenesis was carried out with UV irradiation, cells harvested at the end of exponential growth were recovered in $10 \mathrm{ml}$ of Na phosphate buffer. The suspension was placed in a $90 \mathrm{~mm}$ diameter Petri dish and exposed to UV radiation at $254 \mathrm{~nm}$ (UVSL-58 
centrifuged and resuspended in M17 broth and then treated in the same way as for NTGtreated cells. After mutagenesis, all the mutants were purified at least four times by successive plating on screening medium and selecting individual colonies. The purity and identity of the resulting isolates were then confirmed by several examinations. When cultivated at $30^{\circ} \mathrm{C}$, all the isolates had the following properties (except when stated, all cultures on agar plates where incubated for 2 days before examination): Gram-positive, cocci-shaped and catalase negative microorganisms; blue colonies formed on Kempler \& McKay agar (1980); arginine positive on M16-BCP agar (Thomas, 1973); absence of growth on M17 agar supplemented with $65 \mathrm{~g} / \mathrm{l}$ $\mathrm{NaCl}$; growth on M17 agar supplemented with $20 \mathrm{~g} / \mathrm{l} \mathrm{NaCl}$; fermentation of lactose, galactose, fructose, maltose and ribose when tested on a modified MRS agar (De Man et al. 1960) in which glucose and citrate were omitted, and containing $5 \mathrm{~g} / \mathrm{l}$ of the sugar substrate and $0.05 \mathrm{~g} / \mathrm{l}$ of bromocresol purple; absence of growth on MRS agar supplemented with $20 \mu \mathrm{g} / \mathrm{ml}$ vancomycin when incubated for 5 days. All the isolates grew on M17 agar when incubated for 7 days at $10^{\circ} \mathrm{C}$ or for 2 days at $40^{\circ} \mathrm{C}$. None of the isolates grew on M17 agar at $45^{\circ} \mathrm{C}$. All these properties were also observed when the parent strain was examinated.

\section{Screening medium}

Agar media containing 2,3,5-triphenyl tetrazolium (TTC) were tested for their capacity to detect colonies of Lc. l. l. diacetylactis CNRZ 483 mutants with attenuated LDH activity. These media were prepared from a basic medium called LDHA, derived from M17 broth: tryptone $(2.5 \mathrm{~g})$, papain digest of soybeans $(5 \mathrm{~g})$, peptic digest of meat $(2.5 \mathrm{~g})$, meat extract $(5 \mathrm{~g})$, yeast extract $(2.5 \mathrm{~g}), \mathrm{L}$-ascorbic acid $(0.5 \mathrm{~g})$, magnesium sulphate $(0.25 \mathrm{~g}), \mathrm{K}_{2} \mathrm{HPO}_{4}$ $(0.5 \mathrm{~g})$, glucose $(10 \mathrm{~g})$, and agar $(15 \mathrm{~g})$. The ingredients were dissolved in 11 of distilled water and $\mathrm{pH}$ was adjusted to 7 with hydrochloric acid. The medium was autoclaved at $115^{\circ} \mathrm{C}$ for 15 
(10 g/l) were added. The medium was poured into $140 \mathrm{~mm}$ diameter Petri dishes which were incubated at $30^{\circ} \mathrm{C}$ for $48 \mathrm{~h}$ after inoculation.

\section{Measurement of $\mathrm{CO}_{2}$ production}

Skimmed ewes milk powder was obtained from the Société des Caves (F-12250 Roquefort-sur-Soulzon, France). It contained $407.6 \mathrm{~g}$ of lactose and $439.5 \mathrm{~g}$ of total protein per kg. Growth in this medium was similar to that in fresh ewes milk, but higher than in skimmed cows milk, probably because of the lower buffering capacity of the latter (J.-P. Reverbel, personal communication). Following a $24 \mathrm{~h}$ preculture at $30^{\circ} \mathrm{C}$ in $5 \mathrm{ml}$ of $\mathrm{M} 17$ broth, the strains were inoculated at the concentration of $1 \%$ in $20 \mathrm{ml}$ of reconstituted skimmed ewes milk $(130 \mathrm{~g} / \mathrm{l})$ that had been sterilised at $110^{\circ} \mathrm{C}$ for $15 \mathrm{~min}$. The $60 \mathrm{ml}$ culture vessels with a magnetic stirring bar were then sealed with a rubber septum and an aluminium capsule. After incubating for $24 \mathrm{~h}$ at $30^{\circ} \mathrm{C}$, gas production was determined as described by Kihal (1995). The method involves measuring the displacement of a column of water in a $40 \mathrm{ml}$ graduated burette. The bottom of the burette was immersed in a water tank and the top was closed with a tap linked to a syringe, whose function was to adjust the water level to zero at the start of the measurement. All measurements were done at $20^{\circ} \mathrm{C}$. The septum of the vessels was pierced with a needle connected to the top of the burette filled with water and $3 \mathrm{ml}$ of $2 \mathrm{M} \mathrm{HCl}$ were added to the vessel with a syringe and needle. The volume of water displaced was measured after stirring the culture for $3 \mathrm{~min} . \mathrm{CO}_{2}$ production by cultures was calculated by considering that one mole of $\mathrm{CO}_{2}$ is equivalent to a volume of 24.041 (at $20^{\circ} \mathrm{C}$ and $1 \mathrm{~atm}$.). It was observed that a portion of the $\mathrm{CO}_{2}$ remained in the medium in the form of $\mathrm{H}_{2} \mathrm{CO}_{3}$, because of the presence of $\mathrm{CO}_{2}$ in the gas phase. In order to assay total $\mathrm{CO}_{2}$, it was necessary to calibrate the system, e.g. with sodium bicarbonate in milk. The following relationship was obtained by polynomial regression: 


$$
B=-0.0014 . A^{2}+1.4768 . A \quad\left(r^{2}=0.999\right)
$$

where $\mathrm{A}$ is $\mathrm{CO}_{2}$ production (in $\mathrm{mM}$ ) that does not take into account the $\mathrm{CO}_{2}$ remaining in the medium and $\mathrm{B}$ is the corrected production of $\mathrm{CO}_{2}$.

In practice, it would also be possible to use a linear regression $(\mathrm{B}=1.3035$. A), but this 5 possibility was not retained here because the value of $r^{2}$ was slightly lower (0.995). The coefficients of variation of $\mathrm{CO}_{2}$ production measurements were generally close to $3 \%$. 


\section{RESULTS}

Development of a method for screening mutants with attenuated lactate dehydrogenase activity

Many microorganisms reduce TTC to formazan, an insoluble compound that colours colonies red or brown, but TTC reduction does not occur in acidic culture media (Lederberg, 1948). Hillman (1978) applied this principle to develop a medium for screening LDHdeficient mutants of Streptococcus mutans. We sought conditions for the screening of Lc. l. l. diacetylactis CNRZ 483 mutants with attenuated LDH activity by varying the buffering capacity of LDHA medium by supplementing it with different quantities of sodium glycerophosphate. At the concentration of $20 \mathrm{~g} / \mathrm{l}$, strain CNRZ 483 formed white colonies. In the same conditions, mutant $483 \mathrm{~L} 1$ whose $\mathrm{LDH}$ activity was $9 \%$ that of the parental strain (Boumerdassi et al. 1997) formed colonies with a brown centre. Mutant 483L2 whose LDH activity was only $0.3 \%$ that of the parental strain formed colonies that were entirely brown. At a concentration of $40 \mathrm{~g} / \mathrm{l}$ of glycerophosphate, both the parent strain and the mutants formed brown colonies. At lower concentrations of glycerophosphate $(0,5$ and $10 \mathrm{~g} / \mathrm{l})$ the parent strain and mutant 483L1 formed white colonies, whereas mutant 483L2 formed colonies that were entirely brown or had a brown centre. LDHA medium supplemented with $20 \mathrm{~g} / \mathrm{l}$ of glycerophosphate, called LDHA-20, was thus used in the remainder of this work to screen for mutants. It enabled the distinction of one colony of mutant $483 \mathrm{~L} 1$ or $483 \mathrm{~L} 2$ on a Petri dish among more than 1000 colonies of the parental strain.

\section{Selection of mutants on LDHA-20 agar}

The effect of the UV dose and NTG concentration on the survival of Lc.l. $l$. 
cell viability decreased linearly with the intensity of mutagen treatment. Four mutagenic treatments were then used to screen for mutants forming brown colonies on LDHA-20 agar (Table 1): incubation of the cells in the absence of NTG (spontaneous mutation), in the presence of $20 \mu \mathrm{g} / \mathrm{ml} \mathrm{NTG}$, in the presence of $200 \mu \mathrm{g} / \mathrm{ml} \mathrm{NTG}$, and after UV irradiation at

$5 \quad 44.7 \mathrm{~J} / \mathrm{m}^{2}$. The highest frequency of brown colonies was obtained with $200 \mu \mathrm{g} / \mathrm{ml}$ of NTG. This frequency decreased by a factor of about two when the NTG concentration was $20 \mu \mathrm{g} / \mathrm{ml}$, by a factor of about 20 with UV treatment and by a factor of about 200 for spontaneous mutation.

After each mutagen treatment, mutants forming brown colonies on LDHA-20 agar were ranked as a function of their $\mathrm{CO}_{2}$ production (Table 2). For the four mutagen treatments, about half the mutants produced between 15 and $30 \mathrm{mM} \mathrm{CO}_{2}$, equivalent to the same or slightly higher production as the parental strain that produced $18 \mathrm{mM}$. In contrast to spontaneous and UV-induced mutants, a portion of the NTG-induced mutants produced less than $15 \mathrm{mM} \mathrm{CO}_{2}$. Some spontaneous mutants produced more than $90 \mathrm{mM} \mathrm{CO}_{2}$, whereas some NTG and UV-induced mutants produced more than $105 \mathrm{mM}$ of gas. Compared to the total number of colonies screened (i.e. the number of white colonies plus the number of brown colonies), the percentages of mutants whose $\mathrm{CO}_{2}$ production was higher than $45 \mathrm{mM}$ were $0.001,0.109,0.165$ and $0.008 \%$ for spontaneous mutation, mutagenesis with $20 \mu \mathrm{g} / \mathrm{ml}$ of NTG, $200 \mu \mathrm{g} / \mathrm{ml}$ of NTG, and UV, respectively. 


\section{DISCUSSION}

The LDHA-20 medium enabled colonies of parental strain of Lc. l. l. diacetylactis CNRZ 483 to be distinguished from those of mutated strains exhibiting attenuated LDH activity. It contains TTC, a redox indicator that can be reduced to formazan by most lactic acid bacteria. It is important to emphasise, however, that TTC is reduced only if the $\mathrm{pH}$ is not excessively acid (Lederberg, 1948). Acidifying parental strains thus form white colonies, while mutants with attenuated LDH activity form brown colonies resulting from the formation of a formazan precipitate. Colony colour thus depends on the balance between their acidifying and reducing capacities. In general, formazan precipitates are red. The fact that the precipitates observed on LDHA-20 agar were brown was probably due to the effect of some components present in the medium. Up to now, we have tested 24 different strains of Lc.l. l. diacetylactis on LDHA-20 agar. Twenty two of them exhibited the same behaviour as strain CNRZ 483, forming white colonies on LDHA-20 agar, whereas colonies were brown when the glycerophosphate concentration was increased to $40 \mathrm{~g} / \mathrm{l}$. Two strains formed brown colonies on LDHA-20, but the colonies where white when the glycerophosphate concentration was between 0 and $10 \mathrm{~g} / \mathrm{l}$. For the latter type of strains, it is necessary to reduce the concentration of glycerophosphate in the screening medium to $10 \mathrm{~g} / 1$ to correctly distinguish wild-type colonies from mutants. It was easier to use LDHA-20 medium to screen for mutants with attenuated LDH activity than the medium described by Boumerdassi et al. (1997). LDHA-20 in fact enabled a larger number of colonies per Petri dish to be examined (1000 vs. 150) and did not require treatments of the Petri dishes after the growth of colonies (replica plating on velvet and staining with $\alpha$-naphthol). It was thus possible to select mutants in a cell suspension containing a very low proportion of mutants, e.g. in the case of screening for spontaneous mutants. 
It was observed that about half of the mutants forming brown colonies on LDHA-20 agar produced a similar amount of $\mathrm{CO}_{2}$ than the parent strain. Several types of mutations may lead to such strains. For example, mutants having the same acidifying capacity as the parental strain, but an increased reducing capacity, should form brown colonies without producing excess $\mathrm{CO}_{2}$. Also, several mutants forming brown colonies on LDHA-20 agar may have mutations resulting in a poor growth in milk that would decrease their ability to produce large quantities of $\mathrm{CO}_{2}$. Such mutants would have no technological interest, which is why it is necessary to add a second stage after selecting mutants on LDHA-20 agar, i.e. the measurement of $\mathrm{CO}_{2}$ production in milk cultures. The procedure described in materials and methods has the advantage of being very precise and simple to use in practice.

The present work centred around the development of a method for the selection of mutants producing excess $\mathrm{CO}_{2}$. The mutants that were selected will be studied in relation to their metabolism of lactose and citrate in milk, their LDH activity, and their stability. de Roquefort) for his helpful suggestions. This work was partially supported by the European Union (contract AIR3-CT94-2010). A. El Attar is the recipient of a Franco-Egyptian cooperation fellowship from the French Foreign Affairs Ministry. 


\section{REFERENCES}

Boumerdassi, H., Monnet, C., Desmazeaud, M. \& Corrieu, G. 1997 Isolation and properties of lactococcus lactis subsp. lactis biovar diacetylactis CNRZ 483 mutants producing diacetyl and acetoin from glucose. Applied and Environmental microbiology 63 2293-2299

De Man, J. C., Rogosa, M. \& Sharpe, M. E. 1960 A medium for cultivation of lactobacilli. Journal of Applied Bacteriology 23 130-135

Devoyod, J. J. \& MulleR, M. 1969 [The microbial flora of Roquefort cheese III. The lactic streptococci and the leuconostocs. Influence of different contamination microorganisms.] Lait 487 369-399

HILLMAN, J. D. 1978 Lactate dehydrogenase mutants of streptococcus mutans: isolation and preliminary characterization. Infection and Immunity 21 206-212

KIHAL, M. 1995 [Study of the carbon dioxyde production by Leuconostoc mesenteroides, Application to blue-veined cheese technologies] $\mathrm{PhD}$ thesis, University es-senia, Oran, Algeria

KEMPLER, G. M. \& MCKAY, L. L. 1980 Improved medium for detection of citrate-fermenting Streptococcus lactis subsp. diacetylactis. Applied and Environmental Microbiology 39 926927

20 LEDERBERG, J. 1948 Detection of fermentative variants with tetrazolium. Journal of Bacteriology 56695

Martley, F. G. \& Crow, V. L. 1996 Open texture in cheese: the contributions of gas production by microorganisms and cheese manufacturing practices. Journal of Dairy Research 63 489-507 
MC KAY, L. L. \& BALDwIN, K. A. 1973 Altered metabolism in a Streptococcus lactis C2 mutant deficient in lactic dehydrogenase. Journal of Dairy Science 57 181-186

TERZAGHI, B. E. \& SANDINE, W. E. 1975 Improved medium for lactic streptococci and their bacteriophages. Applied Microbiology 29 807-813

5 Thomas, T. D. 1973 Agar medium for differentiation of Streptococcus cremoris from other bacteria. New Zealand Journal of Dairy Science \& Technology 8 70-71 


\section{FIGURE LEGENDS}

Fig. 1. Effect of the $N$-methyl- $N$ '-nitro- $N$-nitrosoguanidine (NTG) concentration (๑) or the dose of UV radiation (O) on the viability of Lactococcus lactis subsp. lactis biovar. diacetylactis RD311 cells.

10

Dosage of u.v. irradiation, $\mathrm{J} / \mathrm{m}^{2}$

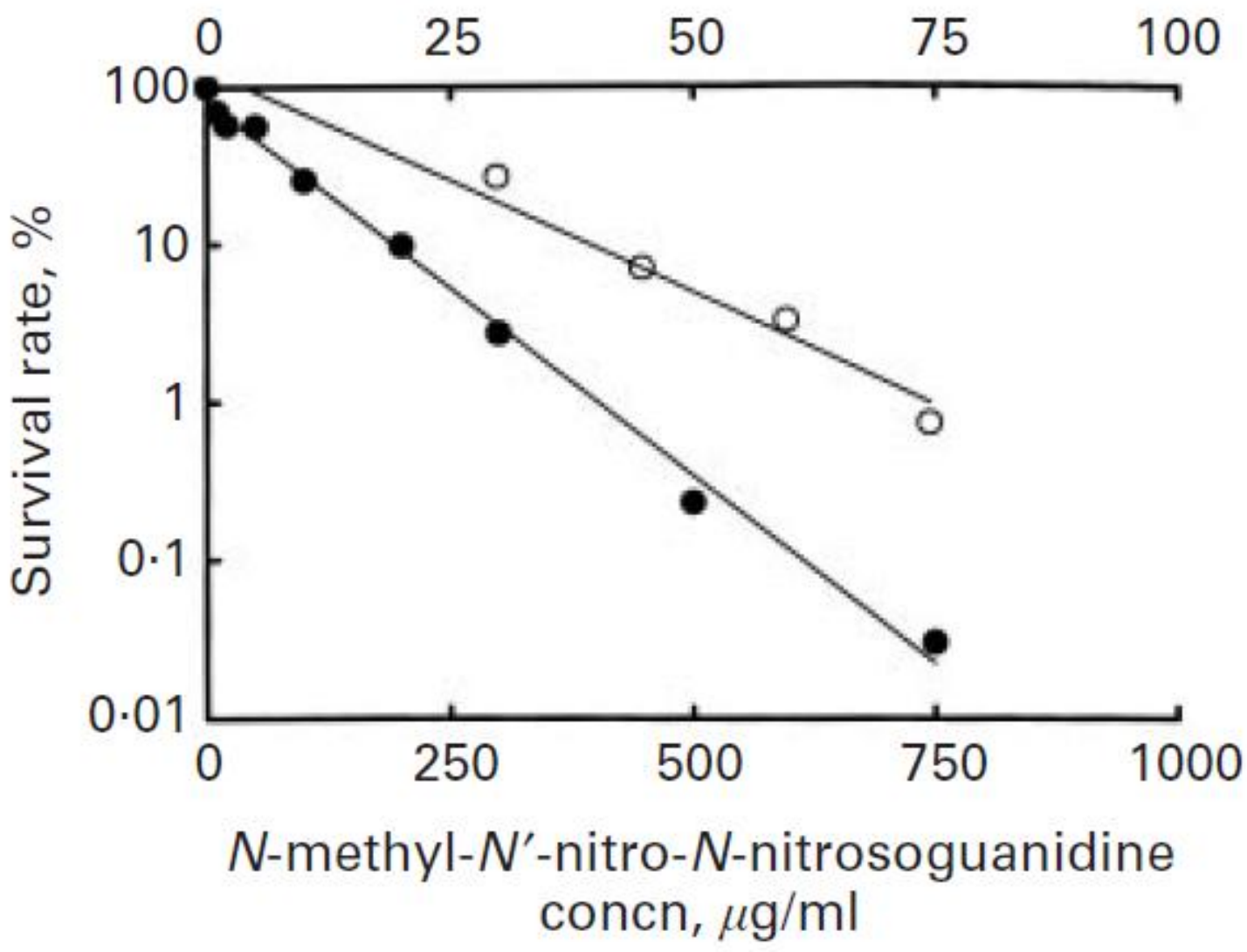


Table 1. Selection of mutants of Lactococcus lactis subsp. lactis biovar. diacetylactis RD311 forming brown colonies on LDHA-20 agar ${ }^{\dagger}$

\begin{tabular}{|c|c|c|c|c|}
\hline Mutagen treatment & Survival rate (\%) & $\begin{array}{c}\text { Number of colonies } \\
\text { examined }\end{array}$ & $\begin{array}{c}\text { Number of brown } \\
\text { colonies }\end{array}$ & $\begin{array}{l}\text { Frequency of brown } \\
\text { colonies }(\%)\end{array}$ \\
\hline $\begin{array}{l}\text { Incubation in the } \\
\text { absence of NTG }\end{array}$ & 100.0 & $4.1 \times 10^{5}$ & 17 & $4.1 \times 10^{-3}$ \\
\hline $\begin{array}{l}\text { Incubation with } 20 \\
\mathrm{\mu g} / \mathrm{ml} \text { of NTG }\end{array}$ & 56.8 & $3.5 \times 10^{4}$ & 124 & $3.5 \times 10^{-1}$ \\
\hline $\begin{array}{l}\text { Incubation with } 200 \\
\mu \mathrm{g} / \mathrm{ml} \text { of NTG }\end{array}$ & 9.8 & $1.7 \times 10^{4}$ & 121 & $7.1 \times 10^{-1}$ \\
\hline $\begin{array}{l}\text { UV irradiation at the } \\
\text { dose of } 44.7 \mathrm{~J} / \mathrm{m}^{2}\end{array}$ & 7.0 & $3.0 \times 10^{5}$ & 100 & $3.3 \times 10^{-2}$ \\
\hline Defined in text & & & & \\
\hline
\end{tabular}


Table 2. $\mathrm{CO}_{2}$ production by mutants of Lactococcus lactis subsp. lactis biovar. diacetylactis RD311 forming brown colonies on LDHA-20 agar $^{\dagger}$

Number of mutants per class of $\mathrm{CO}_{2}$ production (\%)

$\begin{array}{lcccc}\begin{array}{c}\mathrm{CO}_{2} \text { production } \\ \text { range }(\mathrm{mM})\end{array} & \text { Spontaneous mutants } & \begin{array}{c}\text { Mutants with 20 } \\ \mu \mathrm{g} / \mathrm{ml} \text { of NTG }\end{array} & \begin{array}{c}\text { Mutants with 200 } \\ \mu \mathrm{g} / \mathrm{ml} \text { of NTG }\end{array} & \begin{array}{c}\text { Mutants with UV } \\ \text { irradiation at } 44.7 \\ \mathrm{~J} / \mathrm{m}^{2}\end{array} \\ -15 & 0.0 & 4.0 & 14.0 & 0.0 \\ 5-30 & 41.2 & 44.3 & 44.6 & 52.0 \\ 0-45 & 35.3 & 21.0 & 17.4 & 23.0 \\ 5-60 & 17.6 & 8.1 & 8.3 & 5.0 \\ 60-75 & 0.0 & 4.0 & 5.0 & 2.0 \\ 5-90 & 0.0 & 0.8 & 7.4 & 8.0 \\ 0-105 & 5.9 & 7.3 & 2.5 & 5.0 \\ 05-120 & 0.0 & 10.5 & 0.8 & 5.0\end{array}$

$5{ }^{\dagger}$ Defined in text

${ }^{\ddagger} \mathrm{NTG}, N$-methyl- $N$-nitro- $N$-nitrosoguanidine 